\title{
Synthesis, Characterization and Performance of Robust Poison-resistant Ultrathin Film Yttria Stabilized Zirconia - Nickel Anodes for Application in \\ Solid Electrolyte Fuel Cells
}

\author{
F.J. Garcia-Garcia ${ }^{a^{*}}$, F. Yubero ${ }^{a}$, J.P. Espinós ${ }^{a}$, A.R. González-Elipe ${ }^{a}$, R.M. Lambert ${ }^{a, b}$ \\ ${ }^{a}$ Laboratory of Nanotechnology on Surfaces. Instituto de Ciencia de los Materiales de Sevilla \\ (CSIC-Universidad de Sevilla), Avda. Américo Vespucio 49, 41092 Sevilla, Spain \\ ${ }^{\mathrm{b}}$ Chemistry Department, Cambridge University, Cambridge CB2 1EW, United Kingdom \\ *corresponding author: fj.garcia@csic.es; Tel +34 954 489500; Fax +34 954460665
}

\begin{abstract}
We report on the synthesis of undoped $\sim 5$ micron YSZ-Ni porous thin films prepared by reactive pulsed DC magnetron sputtering at an oblique angle of incidence. Pre-calcination of the amorphous unmodified precursor layers followed by reduction produces a film consisting of uniformly distributed tilted columnar aggregates having extensive three-phase boundaries and favorable gas diffusion characteristics. Similarly prepared films doped with 1.2 at. \% $\mathrm{Au}$ are also porous and contain highly dispersed gold present as $\mathrm{Ni}-\mathrm{Au}$ alloy particles whose surfaces are strongly enriched with Au. With hydrogen as fuel, the performance of the undoped thin film anodes is comparable to that of $10-20$ times thicker
\end{abstract}


typical commercial anodes. With a 1:1 steam/carbon feed, the un-doped anode cell current rapidly falls to zero after $60 \mathrm{~h}$. In striking contrast, the initial performance of the Au-doped anode is much higher and remains unaffected after 170 hours. Under deliberately harsh conditions the performance of the Au-doped anodes decreases progressively, almost certainly due to carbon deposition. Even so, the cell maintains some activity after 3 days operation in dramatic contrast with the un-doped anode, which stops working after only three hours of use. The implications and possible practical application of these findings are discussed.

\section{Keywords:}

Magnetron sputtering; Oblique angle deposition; Thin film anodes; Carbon-tolerant; SOFC.

\section{Introduction}

The potential of solid oxide fuel cells (SOFC) for clean, efficient power generation is widely recognized and has given rise to a very large body of research. One of the principal obstacles to large-scale implementation of SOFCs is that of limited anode lifetime caused by the severe operating conditions. The most widely used anodes are nickel-yttria stabilized zirconia cermets (YSZ-Ni) which are inexpensive and possess favorable electrical, catalytic and electrocatalytic properties, especially with respect to the use of hydrocarbon fuels, most notably methane. However, nickel is also very active for hydrocarbon cracking, leading 
eventually to gross carbon deposition, anode deactivation and mechanical failure. The subject has recently been reviewed in detail by Wang et al. [1] and very recently by Petrakopoulou et al. [2].

A variety of remediation strategies have been explored, including modification of the cermet's metallic and oxidic components, thermodynamic mitigation by means of internal steam reforming, and addition of a variety of dopants $[1,2]$. In regard to the latter approach, Gavrielatos et al. [3] showed that the performance of thick YSZ-Ni anodes prepared by a combustion method and operated in $\mathrm{CH}_{4}$ /steam could be significantly improved by addition of small amounts of Au. Their findings prompted the present work in which uniform, thermally robust, highly porous, un-doped and Au-doped YSZ-Ni thin film anodes were deposited on a YSZ electrolyte substrate by magnetron sputtering at an oblique angle of deposition (hereafter referred to as MS-OAD) [4]. We have previously demonstrated that this procedure yields porous columnar (as opposed to dense) anode films that are robust against morphological changes under thermal cycling in both oxidizing and reducing atmospheres, and which resist delamination from the underlying YSZ substrate [5]. Moreover, the MS-OAD method yields films with high and well-defined porosity [6-8]. This is an important asset in the present context in that such porous films have very extensive three-phase boundaries that maximize electrochemical performance in comparison to dense films produced by conventional normal incidence sputtering [9]. In regard to the synthesis of actual YSZ-Ni cermet anodes, both with and without Au doping, we show here that precalcination of the precursor films prior to reduction is critically important to the formation of 
well-structured homogeneous films. These two types of thin film anode were characterized in detail and then tested in a fuel cell fed with either hydrogen or methane + steam. The Audoped ( 1\%) YSZ-Ni anodes exhibited far superior performance with respect to carbon deposition compared to their un-doped counterparts, due to formation of $\mathrm{Ni}$-Au alloy nanoparticles whose surfaces were strongly Au-enriched. These poison-resistant Au-doped anodes are promising candidates for practical use as anodes in their own right. Moreover, as their thinness and porous morphology renders them robust against thermally-induced strain at the anode/YSZ electrolyte interface, they could also be used as highly conducting, stabilizing buffer layers between conventional functional anodes and the YSZ electrolyte; or as poison-resistant capping layers located on top of conventional thick film anodes.

\section{Experimental: synthesis and characterization}

Unmodified and Au-doped YSZ-Ni porous thin films were prepared by reactive pulsed DC magnetron sputtering using a power of $200 \mathrm{~W}, 80 \mathrm{kHz}$ frequency and a working pressure of 5

$\times 10^{-3}$ mbar. Before deposition, the chamber was maintained at a base pressure of $3 \times 10^{-6}$ mbar using as plasma gas a mixture of $40 \mathrm{sccm} \mathrm{Ar}$ and $2.5 \mathrm{sccm} \mathrm{O} \mathrm{O}_{2}$. Commercially available solid oxide half-cells comprising electrolyte (YSZ) and cathode (20 mm Single Electrode Cell Cathode Only, FuelCellMaterials, USA) were used as the substrates for electrochemical experiments performed with a commercial instrument (ProboStat, Norway). In these fuel cell experiments $100 \mathrm{sccm}$ of pure $\mathrm{H}_{2}$ or $10 \mathrm{sccm} \mathrm{CH}_{4}+90 \mathrm{sccm} \mathrm{Ar}+10 \%$ steam was fed to the anode chamber and air was supplied to the cathode chamber at a flow rate of $100 \mathrm{sccm}$. Pt mesh was used as the current collector for both anode and cathode. An electrochemical 
workstation (AUTOLAB, PGSTAT30) with a four-probe configuration was used to obtain current-voltage (I-V) and current-power (I-P) characteristics at temperatures of 850 and $800{ }^{\circ} \mathrm{C}$ for $\mathrm{H}_{2}$ and $\mathrm{Ar}+\mathrm{CH}_{4}+$ steam fuels respectively. Analysis of samples, deposited on a YSZ substrate, was by means of scanning electron microscopy (SEM), X-ray diffraction (XRD), time-of-flight secondary ion mass spectrometry (TOF-SIMS), high angle annular dark field (HAADF) scanning transmission electron microscopy (STEM), Rutherford backscattering spectrometry (RBS) and X-ray photoelectron spectroscopy (XPS). (For quantitative RBS analysis of the initially deposited films, silicon was used as substrate to ensure that $\mathrm{Y}$ and $\mathrm{Zr}$ signals were exclusively due to the thin film anode).

Oblique angle thin film deposition was carried out using two different targets: (i) a $50 \mathrm{~mm}$ diameter $\mathrm{Ni} / \mathrm{Zr} / \mathrm{Y}$ alloy (68.8/26.6/4.6 wt.\%) of $99.9 \%$ purity, chosen to produce YSZ films containing $8 \mathrm{~mol} \% \mathrm{Y} 2 \mathrm{O} 3$ and $50 \mathrm{vol} \% \mathrm{Ni}$, and (ii) a similar target incorporating $3 \mathrm{Ni}$ and $1 \mathrm{Au}$ pellets in order to achieve Au doping of the films. The target-substrate distance was $5 \mathrm{~cm}$ with an angle of $80^{\circ}$ between target and substrate normal and the deposition rate was 1.5 $\mu \mathrm{m} \mathrm{h} \mathrm{h}^{-1}$. A more detailed description of the deposition procedure may be found elsewhere [5]. Oblique angle deposition resulted in formation of highly porous anode thin films, crucial for achieving superior structural and electrical properties. The technique is very reproducible, straightforward, and well suited to scale-up, all sample preparations and analyses having been repeated at least twice $[4,9]$. 
The microstructure of films deposited on YSZ was examined by SEM using a Hitachi S4800 field emission microscope. RBS spectra were obtained in a tandem accelerator (Centro Nacional de Aceleradores, Universidad de Sevilla, Spain) with particle energy $1.557 \mathrm{MeV}$, beam current and diameter $1.7 \mathrm{nA}$ and $\sim 1 \mathrm{~mm}$, respectively. The accumulated dose was 1.5 $\mu \mathrm{C}$ in all cases and spectra were analysed by means of the SIMRA6.0 program. XRD patterns were obtained using $\mathrm{Cu} \mathrm{K} \alpha$ radiation with a Panalytical X'Pert Pro diffractometer incorporating a diffracted beam graphite monochromator and 1D silicon strip detector ( $X^{\prime}$ Celerator). They were recorded from $2 \theta 10^{\circ}$ to $90^{\circ}$ with step size $0.026^{\circ}$ at $148 \mathrm{~s}$ per step. Analyses were performed using XPert HighScore Plus software. XPS spectra were recorded with a Phoibos 100 DLD (SPECS) instrument working with a constant pass energy of $20 \mathrm{eV}$. In accord with common practice, the binding energy (BE) scale is referenced to the $C$ 1s peak (284.5 eV) arising from adventitious carbon. ToF-SIMS depth profiling analysis was performed on a ToF-SIMS type ION-TOF V instrument (Universidad de Extremadura, Spain), equipped with a Bipolyatomic primary ion source, a Cs/electron impact dual source column, and a low-energy electron flood gun for charge compensation of insulating samples. HAADFSTEM analysis was performed in a Tecnai20 high resolution TEM.

\section{Results and Discussion}

\subsection{Morphology and structure of YSZ-Ni anodes}

Room temperature deposition produced anode precursor layers that contained poorly crystalline $\mathrm{NiO}$ and exhibited a typical tilted columnar microstructure resulting from 
shadowing effects during growth [4-8]. (The sharp YSZ peaks are due to the substrate). Reduction in $\mathrm{Ar} / 5 \% \mathrm{H} 2$ at $850^{\circ} \mathrm{C}$ resulted in the morphology illustrated in Figures $1 \mathrm{a}, \mathrm{b}$ characterized by marked surface segregation of large Ni particles $(1.5-6 \mu \mathrm{m})$ along with smaller Ni particles (200 - $400 \mathrm{~nm}$ ) interspersed within the YSZ nanocolumns. Other than the relatively large particles atop the film surface, the Ni particles were much smaller than those typical of YSZ-Ni anodes prepared by doctor blade or similar methods, which contain particles of up to $10 \mu \mathrm{m}$ [10-11]. Clearly, decreased $\mathrm{Ni}$ particle sizes with narrow size distribution would improve the performance of such composite films as anodes in SOFC applications. Very substantial improvement can indeed be achieved, as shown below.

In marked contrast with the outcome of the $\mathrm{H}_{2}$-only activation procedure, pre-calcination of the precursor layer in air at $1250^{\circ} \mathrm{C}$ followed by reduction in $\mathrm{Ar} / 5 \% \mathrm{H} 2$ at $850^{\circ} \mathrm{C}$ produced a very different morphology, illustrated in Figures $1 \mathrm{c}, \mathrm{d}$. This consisted of columnar aggregates (diameter $\sim 800 \mathrm{~nm}$ ) of composite material separated by $\sim 80-140 \mathrm{~nm}$ channels and distributed uniformly across the film. The homogeneously dispersed small particles covering the entire external surfaces of the YSZ columns are attributed to Ni particles with a narrow size distribution. This structure should be well suited to the intended application because of (i) the greatly increased $\mathrm{Ni}$ surface area, (ii) very extensive three-phase boundaries and (iii) favorable gas diffusion characteristics due to the inter-columnar voids.

\section{Figure 1}


Corresponding XRD data illustrating the evolution of the YSZ-Ni system under the treatment protocols described are shown above in Figure 2 (left side). YSZ was always present as its cubic phase and the as-deposited film exhibited small broad peaks due to the presence of very small particles of $\mathrm{NiO}$. Calcination in oxygen induced $\mathrm{NiO}$ crystallite growth and subsequent heating in hydrogen effected complete conversion of the nickel-containing phase to crystalline metallic $\mathrm{Ni}$, with crystalline domains $\sim 50 \mathrm{~nm}$ estimated by the Scherrer method, in good agreement with Figure $1 \mathrm{c}, \mathrm{d}$. Ni2p XPS spectra were in good accord with these findings, showing the presence of $\mathrm{NiO}$ at the surfaces of the as-deposited films, and its subsequent complete conversion to metallic $\mathrm{Ni}$ after $\mathrm{H}_{2}$ reduction (supporting information Figure S1).

The metal crystallite size found for the samples pre-calcined in air was similar to those measured in the samples been subjected to $\mathrm{H}_{2}$-only activation procedure [5]. This indicates that the large particles that are produced in the latter case are actually agglomerates of much smaller crystallites.

It is of interest to consider why the two different treatments of the as-deposited precursor films lead to two such very different outcomes. A possible explanation is as follows. The initial morphology of the $\mathrm{NiO}$ component within the as-deposited film consists of very small particles (XRD) and amorphous aggregates well dispersed within the YSZ nanocolums. In 
effect, this NiO effectively "wets" the YSZ. Upon heating in $\mathrm{H}_{2}$, this highly dispersed NiO is rapidly reduced to $\mathrm{Ni}$ metal, which has a much less favorable interaction with the YSZ. Moreover, hydrogen, even at modest temperatures and pressures, greatly enhances the mobility of $\mathrm{Ni}$ [12]. The net result is an efficient growth of large metallic Ni particles which are expelled from the nanocolumnar structure rather than being incorporated in it (SEM).

On the other hand, pre-calcination of the initially deposited precursor causes the highly dispersed $\mathrm{NiO}$ component to undergo particle growth resulting in formation of crystalline $\mathrm{NiO}$ (XRD) distributed over the YSZ component to which it adheres, the two having a favorable oxide-oxide interfacial interaction. During subsequent $\mathrm{H}_{2}$ treatment, the $\mathrm{NiO}$ crystallites act as fixed nucleation centres that undergo conversion to metallic $\mathrm{Ni}$ particles uniformly distributed within the YSZ columnar structure (SEM).

Figure 2

\subsection{Morphology, structure and composition of YSZ-Ni/Au anodes}

We now consider the changes induced by Au doping of the precursor layer. In this case, because $\mathrm{Au}$ melts at $1064^{\circ} \mathrm{C}$, the pre-calcination step was performed at the reduced temperature of $1000^{\circ} \mathrm{C}$ rather than the normally optimum temperature of $1250^{\circ} \mathrm{C}$, to avoid destruction of the film. (SEM showed that calcination at $1250^{\circ} \mathrm{C}$ massively disrupted Audoped films. Supporting information, Figure S2). 
The as-deposited Au-doped precursor YSZ-Ni/Au thin films exhibited a homogenous porous microstructure consisting of thin, tilted nanocolumns (Figure 3(a)) similar to those reported previously for un-doped YSZ-Ni [5]. RBS of the as-deposited film (Figure S3 and Table S1) confirmed that $\mathrm{Au}$ and $\mathrm{Ni}$ were homogeneously distributed throughout the film thickness, with an overall gold content of 1.2 atomic \%.

\section{Figure 3}

ToF-SIMS and RBS measurements were also carried out using a practical YSZ electrolyte as substrate, which allowed analyses to be carried out on heat-treated samples (Figures $4(a, c)$ and S3 respectively). These measurements revealed that $\mathrm{Au}$ (and $\mathrm{Ni}$ ) were distributed through the entire film in the initial as-deposited and finally reduced stages. Due to the limited electrical conductivity of both film and substrate in the intermediate calcined stage, we were unable to obtain useful RBS information in these cases. This problem did not arise when analyzing such samples by ToF-SIMS: enrichment of $\mathrm{Ni}$ (present as $\mathrm{NiO}$ ) atop film surface was observed, accompanied by attenuation of the $\mathrm{Au}, \mathrm{Y}$ and $\mathrm{Zr}$ signals.

\section{Figure 4}

Au4f XP spectra confirmed the presence of metallic gold in the as-deposited and in the finally reduced samples, within the sampling depth of the measurement ( $3 \mathrm{~nm}$ in the 
present case) (Figure $4 \mathrm{~d}$ ). Air calcination at $1000^{\circ} \mathrm{C}$ resulted in the microstructure shown in Figure 3(c, d): again porous but clearly different from that of calcined un-doped YSZ-Ni (supporting information Figure S3(d)). The corresponding XPS indicated a complete absence of $\mathrm{Au}$, implying its diffusion beneath the surface, leaving the NiO overgrowth apparent in Figure $4 \mathrm{~d}$. The as-deposited precursor film (Figure $3 \mathrm{~b}$ ) contained very small Au particles (a few $\mathrm{nm}$; XRD, Figure 2 right, top), invisible to SEM and too small for application of the Scherrer equation. Further, in contrast to the un-doped sample, small NiO particles were also not detected by XRD (Figure 2, right, top). Calcination in air caused Au agglomeration and formation of isolated gold particles within the film (bright dots, Figure 3c) in good accord with the Au4f XP spectra which showed that gold had disappeared from the surface region (supporting information Figure S4b) accompanied by surface segregation of NiO (Figure 3d), whose identity was confirmed by the characteristic Ni2p XP spectra. (This effect was not observed with undoped films and reflects the fact that the method of fabrication resulted in the doped films contained more $\mathrm{Ni}$, which was subsequently expelled during calcination.) Strikingly, subsequent treatment in $\mathrm{Ar} / 5 \% \mathrm{H} 2$ at $850^{\circ} \mathrm{C}$ resulted in the appearance of a strong Au4f XP signal (supporting information Fig S4c) whereas this Au was invisible to XRD (Figure 2 right, bottom panel). Thus (i) calcination followed by (ii) reduction resulted in (i) pronounced agglomeration of Au within the film followed by (ii) very good re-dispersion of $\mathrm{Au}$ within the XPS sampling depth. We ascribe this to the reduction of $\mathrm{NiO}$ to $\mathrm{Ni}$ accompanied by formation of Au-containing Ni particles. This is consistent with the fact that in the final anode film, the metallic Ni XRD peaks were displaced by $0.2-0.4$ o relative to their normal position, due to alloying with gold. These Ni nanoparticles crystallites were $\sim 47 \mathrm{~nm}$, 
very similar to the $\mathrm{Ni}$ crystallite particle size found for the un-doped anode. Strong confirmation of $\mathrm{Ni} / \mathrm{Au}$ alloy formation in the fully processed anode was provided by microstructural STEM imaging using high-angle annular dark-field (HAAD) imaging which provides strong Z-contrast. The HAAD maps showed clearly that $\mathrm{Au}$ and Ni were present in identical regions of the anode surface Figure 5).

\section{Figure 5 Amended}

\subsection{Electrochemical performance of YSZ-Ni and YSZ-Ni/Au thin film anodes}

\subsubsection{With hydrogen as fuel}

Figure 6 (top) shows representative V-I and P-I curves obtained with the two types of anodes using $\mathrm{H}_{2}$ as the fuel. Also shown for comparison are similar curves obtained with a conventional 50 micron thick anode prepared by the doctor blade procedure $(20 \mathrm{~mm}$ NextCell Electrolyte Supported Button Cell, FuelCellMaterials, USA). Thus with $\mathrm{H}_{2}$ as fuel, the electrocatalytic performance of our doped and un-doped MS-OAD anodes are similar, despite significant differences in their morphologies and Ni distributions (Figures $1 \mathrm{c}, \mathrm{d}$ and 3 e, f). The larger initial activation and ohmic losses shown by the undoped anode is due to the reduced connectivity between columns compared to the doped anode [13] (Figures 1c, 1d versus $3 e, 3 f)$. As will be shown, this similarity disappeared when our un-doped and doped anodes were tested in a more realistic (methane + steam) fuel environment. Here, with $\mathrm{H}_{2}$, the only slight different between the two anodes was that YSZ-Ni/Au performed slightly 
better at lower current densities and achieved its maximum power density at lower currents. This effect may be ascribed to a better connectivity within the material as apparent from Figure 1. It is noteworthy that the performance of our thin film anodes is comparable to that of the commercial anode, which was 10 times thicker (5 microns versus 50 microns).

\section{Figure 6}

\subsubsection{With a fuel feed of methane + steam}

In order to evaluate their potential for use under more realistic practical conditions corresponding to internal steam reforming of hydrocarbon fuels, the un-doped and doped anodes were operated in a methane + steam environment with a steam-to-carbon ratio of 1.0. Figure 6 (down) shows typical results for the time evolution of fuel cell current at $0.7 \mathrm{~V}$ using our YSZ-Ni and YSZ-Ni/Au anodes. The difference between the two was spectacular. The un-doped anode current collapsed immediately (note that the $t=0$ current was $0.3 \mathrm{~A} \mathrm{~cm}^{-}$ ${ }^{2}$ and it effectively ceased working after $\sim 60$ hours). In striking contrast, the performance of the Au-doped anode was unaffected after 170 hours.

Based on the presence of highly dispersed $\mathrm{Au}$ in the activated $\mathrm{Ni}(\mathrm{Au}) / \mathrm{YSZ}$ anodes, at least in part alloyed with $\mathrm{Ni}$, a plausible explanation for the observed effects of Au-doping is as follows. Gold and nickel form a surface alloy [14-15]. Indeed, given the relative surface 
energies of $\mathrm{Au}$ and $\mathrm{Ni}$ (1.5 and $2.4 \mathrm{~J} \mathrm{~m}^{-2}$ respectively) strong segregation of Au to the alloy surface is expected [16]. Thus the presence of even a small amount of Au could exert a large effect on the surface chemistry of $\mathrm{Au} / \mathrm{Ni}$ alloy nanoparticles, in the present case by increasing the activation energy to methane dissociation [17], while at the same time destabilizing carbon adsorption $[15,18]$. Clearly, both effects would act to inhibit strongly carbon deposition and resultant poisoning of Au-doped anodes, in accord with our findings. Of course, it is also likely that at a sufficiently high level of $\mathrm{Au}$ doping the $\mathrm{CH}_{4}$-activating catalytic reaction that initiates steam reforming would itself be inhibited. Further studies would be needed to establish what the optimum Au doping level is for any particular anode formulation.

Finally, a series of tests were carried out under very harsh conditions (steam/carbon $=1: 6$ ) intended to induce gross carbon deposition on the Au doped anode; for comparison, corresponding tests were carried out with the un-doped anode. Figure 7 shows a series of successive V-I and P-I curves recorded for the YSZ-Ni/Au anode using steam/carbon = 1:6. Each curve was recorded for a period of $3 \mathrm{~h}$ and it is apparent that both the voltage and the power characteristics decreased progressively, indicating progressive poisoning of the anode surface due to deposited carbon. It is remarkable that the cell maintained some activity even after 3 days operation, which contrasts with the drastic decrease in performance found for the un-doped YSZ-Ni anode (insets to Figure 7) which after only three hours operation exhibited negligible activity, again demonstrating the major benefit of Au doping. 


\section{Figure 7}

\section{Conclusions}

Magnetron sputtering in an oblique angle configuration provides a method for the precise, controlled and reproducible fabrication on a YSZ substrate of thermally robust porous YSZ-Ni thin film anodes.

Small amounts of Au dramatically improve the doped anodes' resistance to carbon deposition, which is ascribed to the presence of highly dispersed gold at the surfaces of the Ni nanoparticles -which consist of a Ni-Au alloy, strongly surface enriched with Au.

Because their thinness renders them resistant to strain-induced separation from the electrolyte substrate, and because the fabrication process is well suited to scale-up, the Audoped anodes are promising candidates for practical use as anodes in their own right. They could also be used as highly conducting, stabilizing buffer layers for accommodating strain between conventional functional anodes and the YSZ electrolyte, or as poison-resistant capping layers located on top of conventional thick film anodes.

Based on the present findings, a further development, to which magnetron sputtering is uniquely well suited, is the fabrication of graded-composition YSZ-Ni thin film anodes in 
which one face, in contact with electrolyte, is pure YSZ; followed by a composition gradient to the other face (YSZ-Ni) in contact with the thick film functional anode. In principle, this could eliminate the problem of differential thermal expansion between electrolyte and anode, thus removing this cause of mechanical failure.

\section{Acknowledgements}

The research leading to these results has received funding from the European Union's Seventh Framework Programme (FP7/2007-2013) for the Fuel Cells and Hydrogen Joint Technology Initiative under the T-CELL project with grant agreement $n^{\circ} 298300$. Support from a MINECO (Spain), grants n MAT2013-40852R and 201560E055, is also acknowledged.

\section{References}

[1] W. Wang, C. Su, Y. Wu, R. Ran, Z. Shao, Progress in solid oxide fuel cells with nickel-based anodes operating on methane and related fuels, Chem. Rev. 113 (2013) 8104-8151.

[2] I. Petrakopoulou, D. Tsiplakides and S. Balomenou, Enhanced carbon deposition tolerance of SOFC anodes under triode operation, Top. Catal. 58 (2015) 1303-1310.

[3] I. Gavrielatos, V. Drakopoulos and S.G. Neophytides, Carbon tolerant Ni-Au SOFC electrodes operating under internal steam reforming conditions, J. Catal. 259 (2008) 75-84.

[4] A. Barranco, A. Borras, A. R. Gonzalez-Elipe, A. Palmero, Perspectives on oblique angle deposition of thin films: From fundamentals to devices, Prog. Mater. Sci. 76 (2016) 59-153. 
[5] F.J. Garcia-Garcia, F. Yubero, A.R. González-Elipe, S.P. Balomenou, D. Tsiplakides, I. Petrakopoulou, R.M. Lambert, Porous, robust highly conducting Ni-YSZ thin film anodes prepared by magnetron sputtering at oblique angles for application as anodes and buffer layers in solid oxide fuel cells, Int. J. Hydrogen Energ. 40 (2015) 7382-7387.

[6] J. Gil-Rostra, M. Cano J.M. Pedrosa F.J. Ferrer, F.J. García-García, F. Yubero, A.R. GonzálezElipe, Electrochromic behavior of $\mathrm{W}_{\mathrm{x}} \mathrm{Si}_{\mathrm{y}} \mathrm{O}_{z}$ thin films prepared by reactive magnetron sputtering at normal and glancing angles, ACS Appl. Mater. Interfaces 4 (2012) 628-638.

[7] F.J. Garcia-Garcia, J. Gil-Rostra, F. Yubero, A.R. González-Elipe, Electrochromism in $W O_{x}$ and $\mathrm{W}_{\mathrm{x}} \mathrm{Si}_{\mathrm{y}} \mathrm{O}_{z}$ thin films prepared by magnetron sputtering at glancing angles, Nanosci. Nanotechnol. Lett. 5 (2013) 89-93.

[8] J. Gil-Rostra, F. García-García, F. Yubero, A.R. González-Elipe, Tuning the transmittance and the electrochromic behavior of $\mathrm{Co}_{x} \mathrm{Si}_{y} \mathrm{O}_{z}$ thin films prepared by magnetron sputtering at glancing angle, Sol. Energy Mater. Sol. Cells 123 (2014) 130-138.

[9] A.A. Solovyev, N.S. Sochugov, S.V. Rabotkin, A.V. Shipilova, I.V. Ionov, A.N. Kovalchuk, A.O. Borduleva, Application of PVD methods to solid oxide fuel cells, Appl. Surf. Sci. 310 (2014) 272-277.

[10] A. Faes, A. Hessler-Wyser, A. Zryd, J. Van herle, A Review of RedOx cycling of solid oxide fuel cells, Membranes 2 (2012) 585-664

[11] Y. Wang, Review of anodic development of solid oxide fuel cell, Project Report, 2012 MVK160 Heat and Mass Transport, May 14, 2012, Lund, Sweden. 
[12] L. Hammer, H. Landskron, W. Nichtl-Pecher, A. Fricke, K. Heinz, K. Müller, Hydrogeninduced restructuring of close-packed metal surfaces: $\mathrm{H} / \mathrm{Ni}(111)$ and $\mathrm{H} / \mathrm{Fe}(110)$, Phys. Rev. B 47 (1993) 15969-15972.

[13] W. Vielstich, A. Lamm, H.A. Gasteiger, Handbook of Fuel Cells: Fundamentals, Technology and Applications, Wiley, John Wiley \& Sons, United Kingdom, 2003.

[14] L.P. Nielsen, F. Besenbacher, I. Stensgaard, E. Lægsgaard, C. Engdahl, P. Stoltze, K.W. Jacobsen, J.K. Nørskov, Initial growth of Au on Ni(110): Surface alloying of immiscible metals, Phys. Rev. Lett. 71 (1993) 754-757.

[15] F. Besenbacher, I. Chorkendorff, B.S. Clausen, B. Hammer, A.M. Molenbroek, J.K. Nørskov, I. Stensgaard, Design of a surface alloy catalyst for steam reforming, Science 279 (1998) 1913-1915.

[16] L. Vitos, A.V. Ruban, H.L. Skriver, J. Kollár, The surface energy of metals, Surf. Sci. 411 (1998) 186-202.

[17] P. Kratzer, B. Hammer, J.K. Nørskov, A theoretical study of $\mathrm{CH} 4$ dissociation on pure and gold-alloyed Ni(111) surfaces, J. Chem. Phys. 105 (1996) 5595-5604.

[18] N.M. Galea, D. Knapp, T. Ziegler, Density functional theory studies of methane dissociation on anode catalysts in solid-oxide fuel cells: Suggestions for coke reduction, J. Catal. 247 (2007) 20-33. 


\section{Figure Captions:}

Figure 1. Cross section (left) and top view (right) SEM micrographs of the YSZ-Ni anode films prepared by MS-OAD at ambient temperature and then activated either by heating in $\mathrm{Ar} / 5 \%$ $\mathrm{H}_{2}(\mathrm{a}, \mathrm{b})$ or by heating in air followed by heating in $\mathrm{Ar} / 5 \% \mathrm{H}_{2}(\mathrm{c}, \mathrm{d})$. See text for details.

Figure 2. XRD data for YSZ-Ni (left) and YSZ-Ni/Au (right) thin films showing structural and chemical evolution as a function or processing. Top: as-deposited precursor layers; middle after calcination in air; bottom: final anodes after reduction in $\mathrm{Ar} / 5 \% \mathrm{H}_{2}$ of previously aircalcined film.

Figure 3. Top: a, b SEM of YSZ-Ni/Au precursor layer. Middle: $\mathbf{c}, \mathbf{d}$ after activation in air. Bottom: e,f after reduction in $\mathrm{Ar} / 5 \% \mathrm{H} 2$.

Figure 4. ToF-SIMS of YSZ-Ni/Au specimen deposited on a practical YSZ electrolyte. a) asdeposited precursor layers; b) after calcination in air; c) final anodes after reduction of previously air-calcined film in $\mathrm{Ar} / 5 \% \mathrm{H}_{2} . \quad$ d) Au4f XPS of YSZ-Ni/Au specimen

Figure 5. HAADF STEM image of finally reduced YSZ-Ni/Au specimen (top, left) and corresponding zoom of the area of analysis (bottom, left). Elemental composition mappings for $\mathrm{Y}, \mathrm{Zr} \mathrm{Ni}$ and $\mathrm{Au}$ are also shown. XRD of finally reduced YSZ-Ni and YSZ-Ni/Au (top, right) thin films showing displacement of $\mathrm{Ni}$ peaks, which is associated to $\mathrm{Ni} / \mathrm{Au}$ alloying.

Figure 6. Top)V-I and P-I curves for the YSZ-Ni and YSZ-Ni/Au anodes with hydrogen as fuel. Curves for a commercial YSZ-Ni reference anode are included for comparison. Bottom) 
Evolution with time of the fuel cell current using a steam:carbon ratio of 1 for both un-doped YSZ/Ni and Au-doped YSZ-Ni anodes.

Figure 7. Evolution of the V-I and P-I curves for the YSZ-Ni/Au anode taken in successive electrocatalytic tests under harsh conditions with steam/carbon $=6$. Inset shows corresponding behavior of un-doped YSZ-Ni anode: note very different $\mathrm{y}$-axis scale. 
Figure 1.
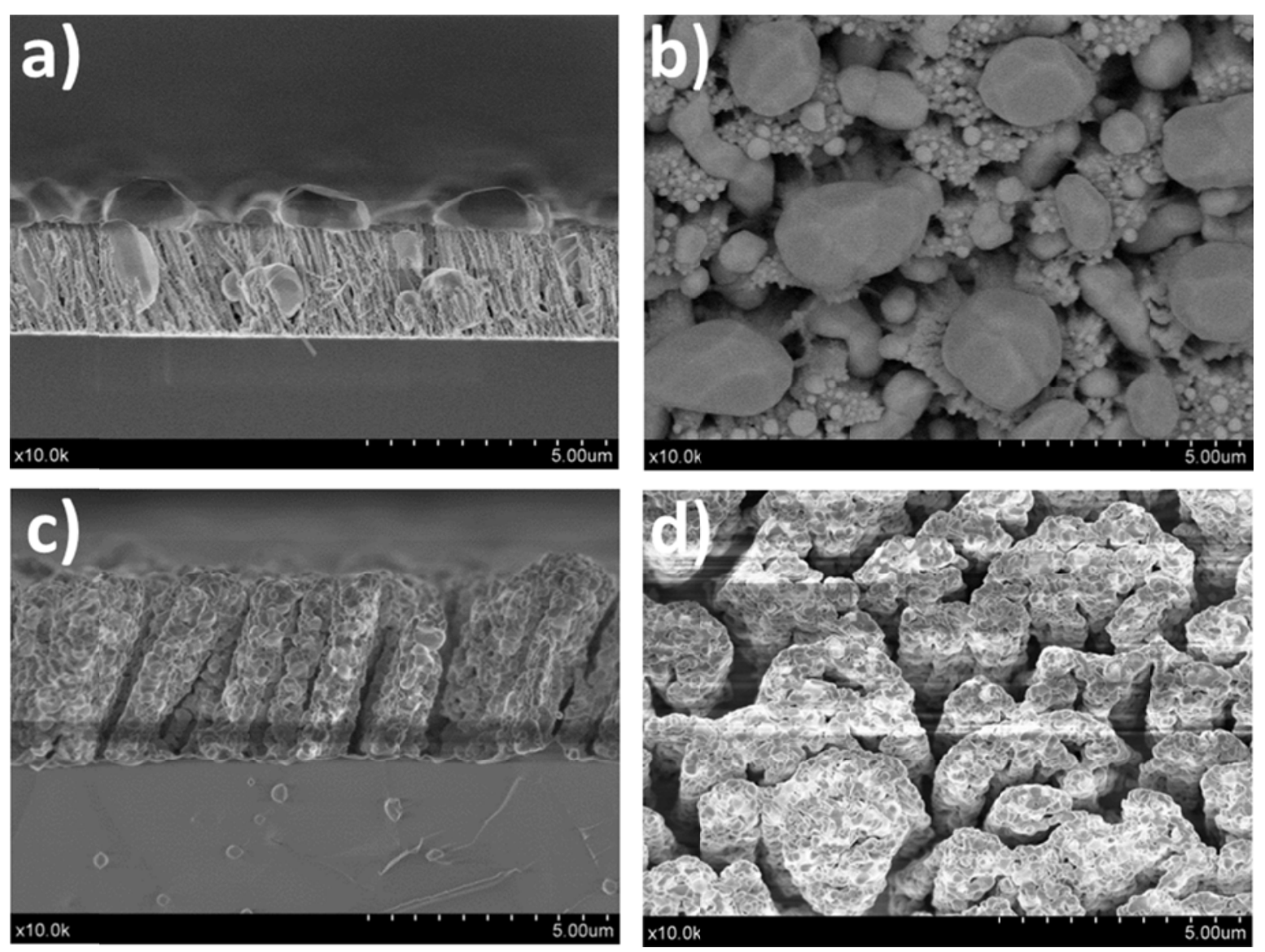
Figure2.

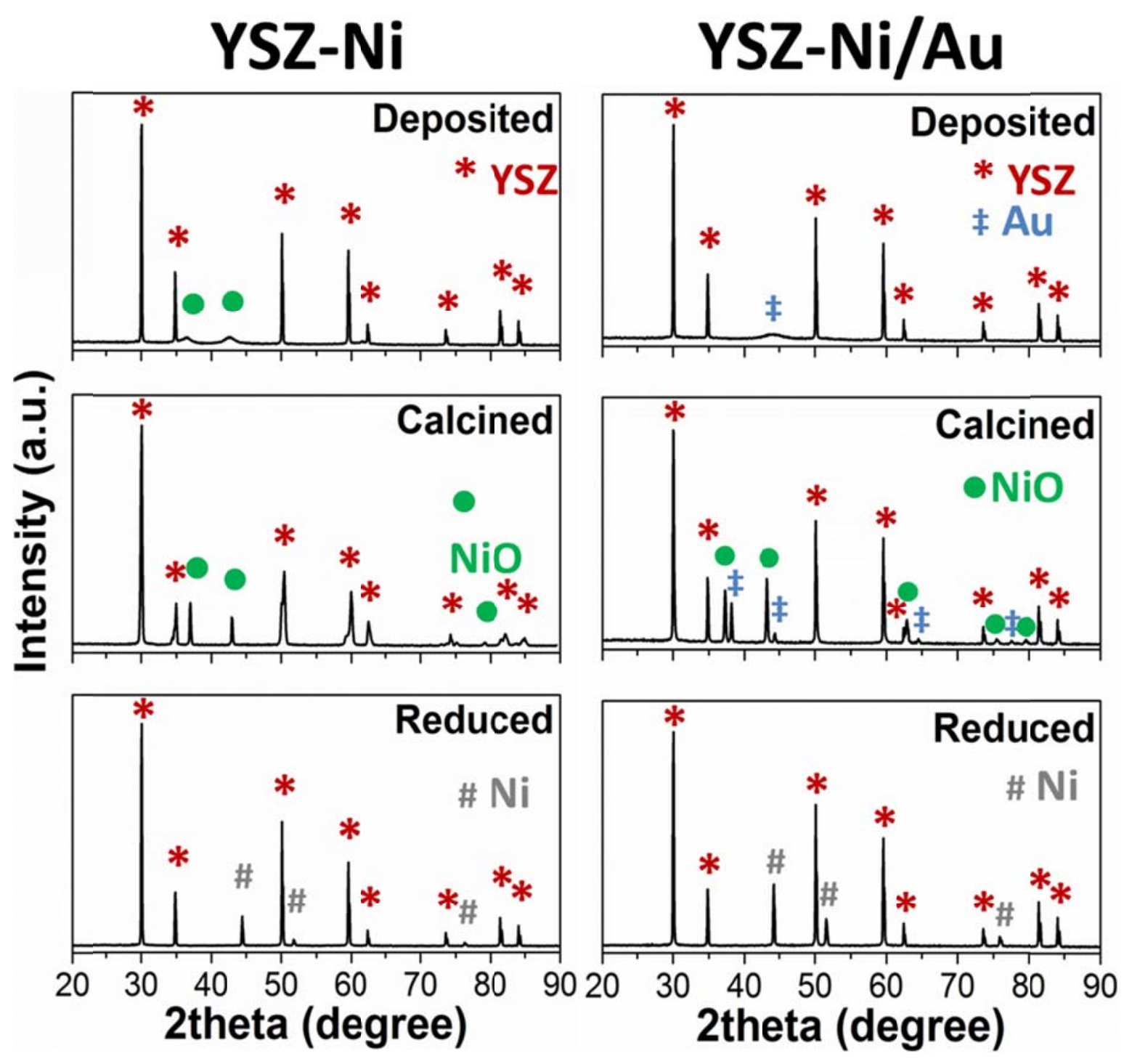


Figure 3.
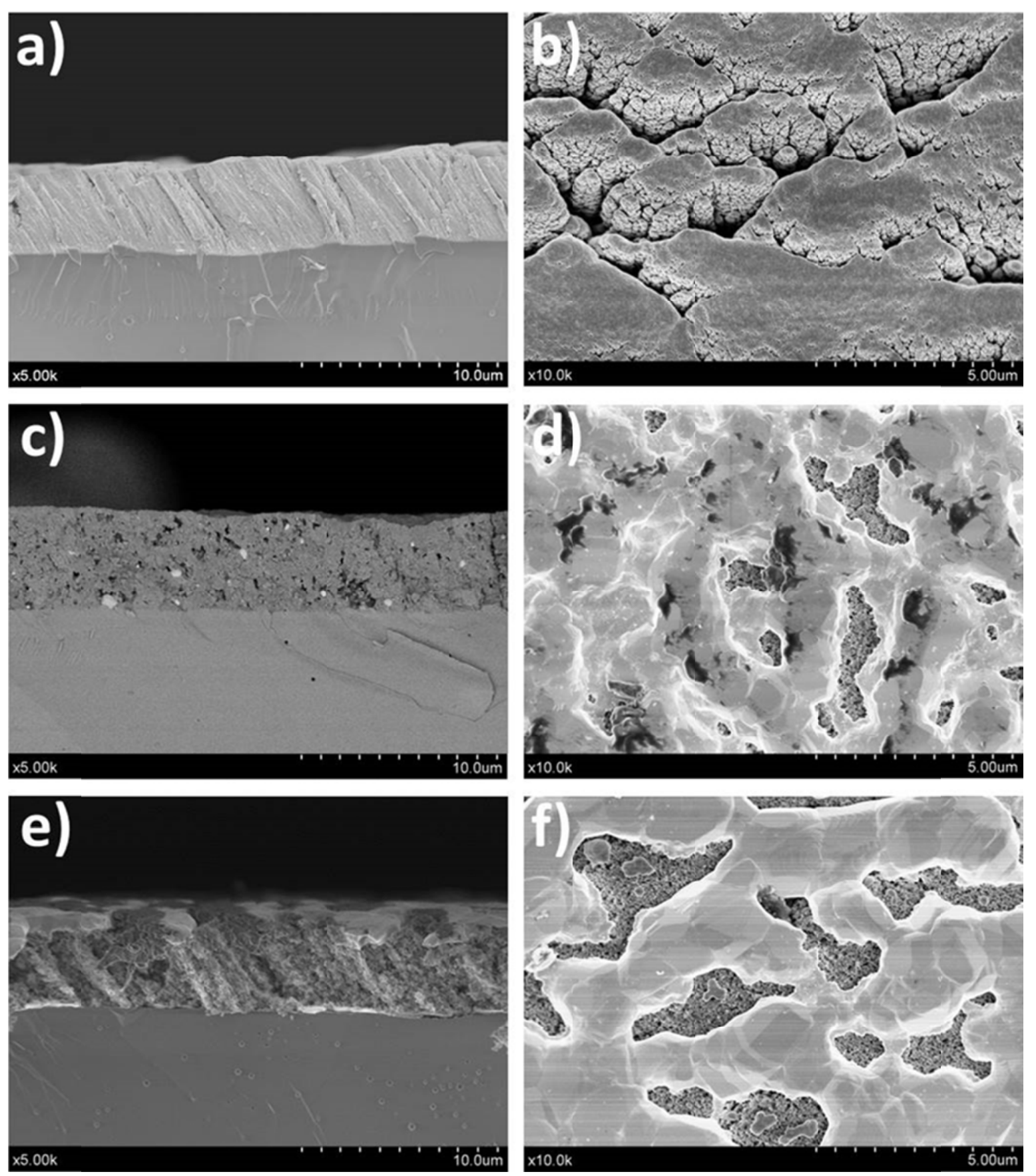
Figure 4.
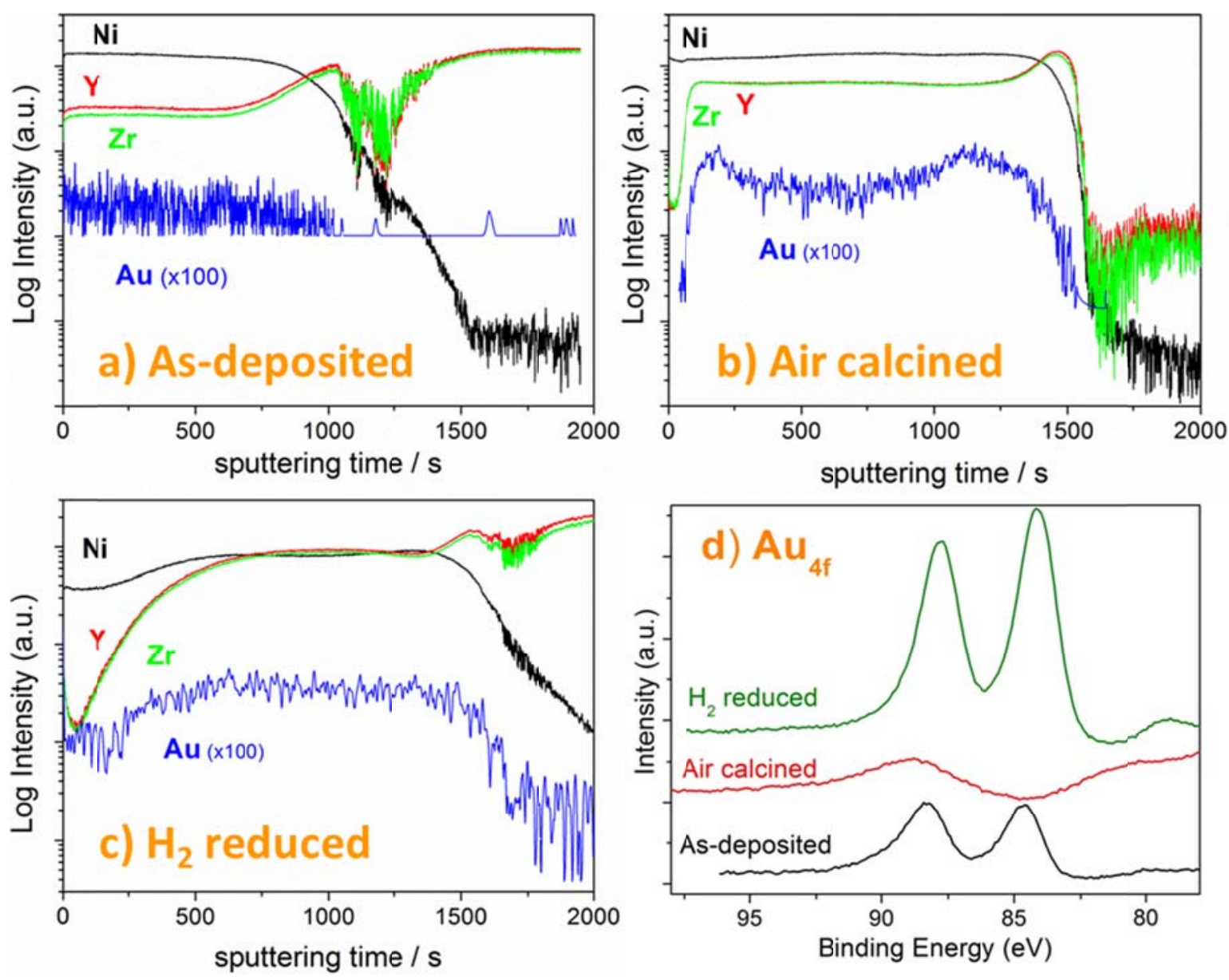
Figure 5.
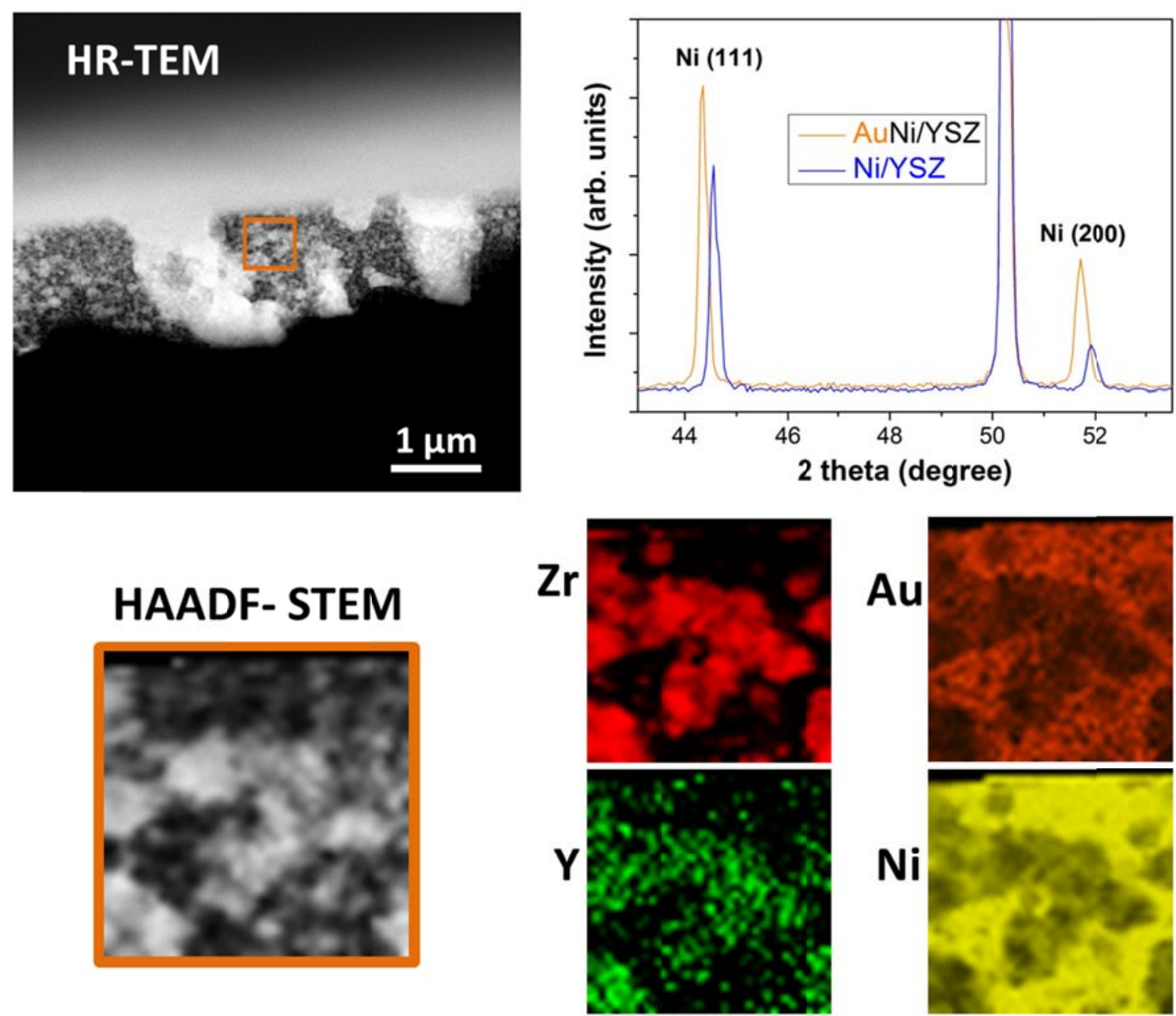

Ni 
Figure 6.
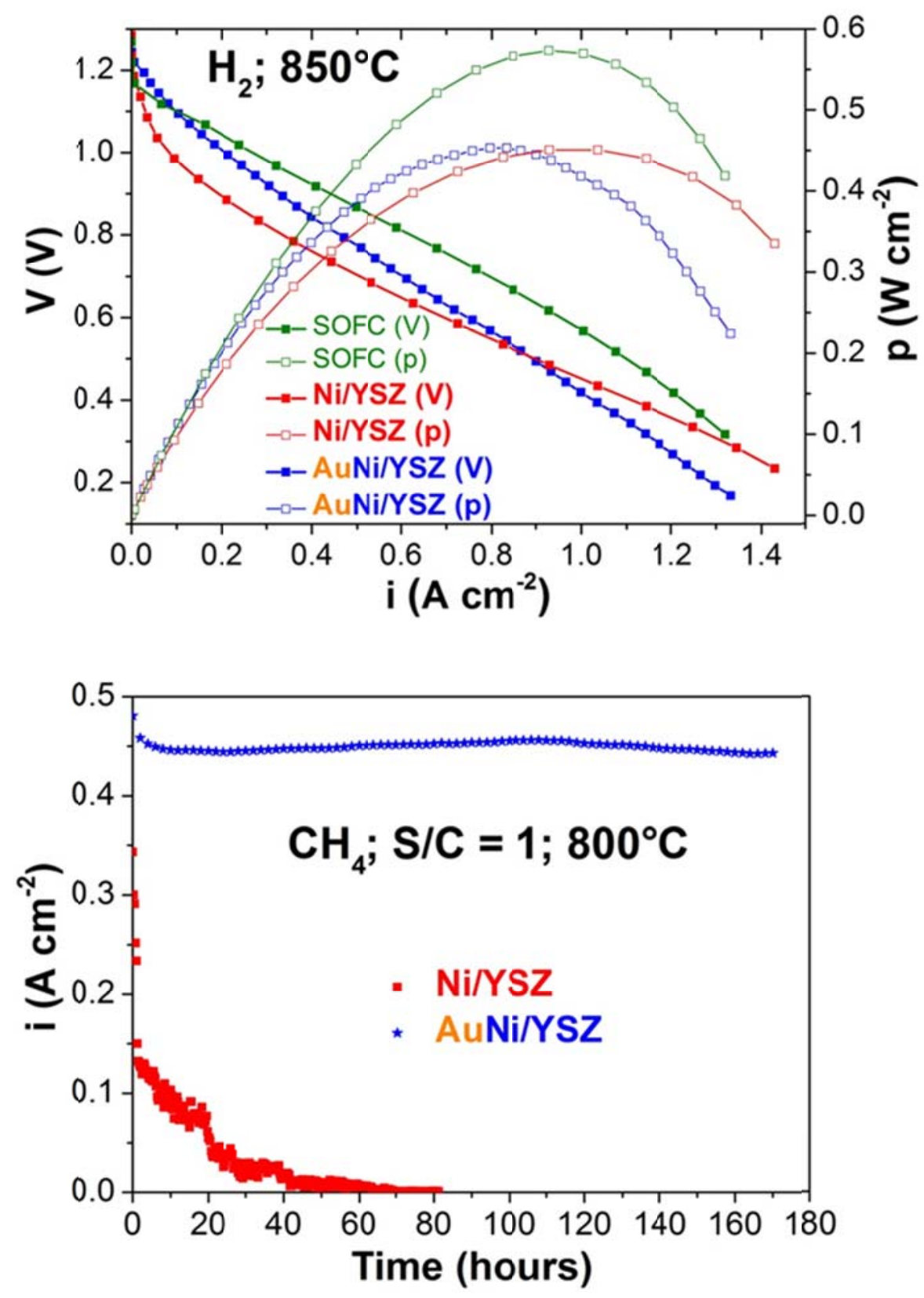